\title{
The Mediating Effects of Social Support and Coping on the Stress-Depression Relationship in Rural and Urban Adolescents
}

\author{
Einar B. Thorsteinsson ${ }^{1}$, Stephanie Mariee Ryan ${ }^{1}$, Sigrun Sveinbjornsdottir ${ }^{2}$ \\ ${ }^{1}$ University of New England, Armidale, Australia \\ ${ }^{2}$ University of Akureyri, Akureyri, Iceland \\ Email: ethorste@une.edu.au
}

Received November $7^{\text {th }}, 2012$; revised December $10^{\text {th }}, 2012$; accepted December $18^{\text {th }}, 2012$

\begin{abstract}
This study examined the relationship between potential risk and protective factors for depression among 167 girls and 343 boys in urban and rural areas of NSW, Australia. The risk and protective factors included social support, coping style, and perceived stress. The results indicated no significant differences in depression and risk and protective factors for rural and urban adolescents. Maladaptive coping (rumination and acting out) and social support (satisfaction and number of supporters) were partial mediators of the relationship between perceived stress and depression with the overall model explaining $66 \%$ of the variance in depression. Thus changes to coping and to social support network need to be addressed in any intervention aimed at reducing the impact of perceived stress on depression in adolescents.
\end{abstract}

Keywords: Social Support; Depression; Coping; Perceived Stress; Adolescent

\section{Introduction}

It is well recognized that adolescence is a major transitional period in a person's life (Dumont \& Provost, 1999) including unusually large cognitive, emotional, social, and physical changes (Seiffge-Krenke, Weidemann, Fentner, Aegenheister, \& Poeblau, 2001). Recent neurobiological research indicates that adolescents, around puberty in particular, may be overly sensitive to stress as compared with children and adults (Romeo, 2010). Adolescence has been described as a sensitive period due to brain development, a phase in the life-span where vulnerability towards development of depression is heightened (Andersen \& Teicher, 2008). In general, adolescents experience stressful situations such as those concerning family relations, school performance, interpersonal relationships (friends and romantic partners), and financial restraints (Byrne, Davenport, \& Mazanov, 2007; Moksnes, Byrne, Mazanov, \& Espnes, 2010). If the demands of these situations exceed the individuals' capacity to cope there will be an increased risk of depression, anxiety, and/or drug and alcohol abuse.

Depression in adolescence has been linked with negative health effects and found to be a predictor of depression in adulthood (Reinherz et al., 1989), especially if it is diagnosed in combination with oppositional defiant disorder, anxiety and substance use (Copeland, Shanahan, Costello, \& Angold, 2009). As many as a quarter of those with major depressive disorder during adulthood have reported onset during childhood or adolescence (Sorenson, Rutter, \& Aneshensel, 1991). For the purpose of prevention, it is important to identify possible protective and risk factors for depression during adolescence.

Findings suggest that protective factors for depression might include adaptive coping (e.g., seeking social support), and high social support (satisfaction with support and network size). Thus, social support has been found to protect against the effects of stress in adults (Cohen \& Wills, 1985) and adolescents (Burke \& Weir, 1978; Levitt, Guacci Franco, \& Levitt, 1993), and to attenuate the effects of stress on psychological problems (Schmeelk-Cone \& Zimmerman, 2003). Several studies have already shown the importance of social support in reducing the impact of stressful situations on cardiovascular reactivity (Thorsteinsson \& James, 1999; Thorsteinsson, James, Douglas, \& Omodei, 2011), suggesting that support plays a causal role in protecting the individual's cardiovascular health. A growing interest for neurobiological aspects of resilience to stress is noted, not least to explore the complex interaction between social support, developmental stage and diverse social factors (Ozbay, Fitterling, Charney, \& Southwick, 2008).

In relation to coping, research shows that well-adapted adolescents use more mature coping strategies than poorly adapted adolescents (Jorgensen \& Dusek, 1990) and they are more active in dealing with stress (Tolor \& Fehon, 1987). Consequently, adolescents who approach their challenges are better adjusted than those who avoid them (Ebata \& Moos, 1991); they have fewer behavioral problems and a higher level of ego development (Recklitis \& Noam, 1999). Avoidant or maladaptive coping, such as rumination and acting out, is repeatedly reported as a risk factor for depression. Thus, rumination is suggested as a vulnerability factor for both adolescent depression and substance use (Skitch \& Abela, 2008). A longitudinal study including early versus late adolescence revealed that when active coping was present in early adolescence it predicted less perceived stress later on towards the same stressors regardless of situations (Seiffge-Krenke, Aunola, \& Nurmi, 2009). However, if internal coping (e.g., withdrawal, rumination) was commonly used in early adolescence then the outcome was reversed with the stress perception being high in late adolescence.

Maladaptive coping such as aggressive or disruptive behavior (acting out, anger) is repeatedly reported as a risk factor for depression and thus it is correlated with greater depression relative to those who use adaptive coping (i.e., problem solving and seeking social support; Galaif, Sussman, Chou, \& Wills, 2003; Jose et al., 1998; Kosterman et al., 2010; Murberg \& Bru, 
2005). Likewise, Murberg and Bru (2005) found that aggressive coping was related to depression and that anger coping sustained depression, perceived stress, and the use of illicit drugs. Seiffge-Krenke and Klessinger (2000) reported that avoidant coping was consistently associated with higher levels of depressive symptoms while approach oriented coping was not. The use of maladaptive coping (e.g., rumination) may thus influence the way adolescents respond to depression and consequently the duration of depressive episodes.

Adolescents in rural areas may be faced with higher levels of depression and stress than adolescents in urban areas. Day, Kane, and Roberts (2000) examined the prevalence rates of stress and depression in rural Western Australia and reported that rural dwellers experience high situational stress on a day-to-day basis including isolation and income factors. Day et al. propose in their review that stress and depression in rural populations might be higher than in urban populations. However, previous research using an adult sample contradicts this suggestion proposing instead that rural populations have lower levels of depression (Crowell, George, Blazer, \& Landerman, 1986). Social geography research into areas such as rural geography, mental health geography, and the social geographies of caring challenges the "idyllic nature of rural life" (Boyd \& Parr, 2008), and suggests that there may be differences between rural and urban populations. Social geography suggests that rural populations have to deal with difficult mental health issues just like urban populations. They also may have to cope with limited resources or access to mental health services (Aisbett, Boyd, Francis, Newnham, \& Newnham, 2007), and individuals with mental illness in rural areas may also feel more isolated from their community (Boyd \& Parr). Quine et al. (2003), in a rural versus urban sample, found higher levels of depression, youth suicide, and teenage pregnancy. They believed this could be explained by a structural imbalance between urban and rural adolescents in Australia because rural adolescents report fewer educational, occupational, and recreational opportunities. In rural adolescent populations, depression has been found to correlate negatively with peer- and family social support, selfesteem, and optimism in rural adolescents (Weber, Puskar, \& Ren, 2010).

Based on the findings reported above, it was hypothesized that 1) rural adolescents would have higher levels of perceived stress and depression than their urban counterparts; 2) low social support would be associated with high depression; 3) high maladaptive coping would be associated with high depression and low social support; 4) social support would mediate (reduce) the effects of perceived stress on depression; 5) adaptive coping would mediate (reduce) the effects of perceived stress on depression; and 6) that maladaptive coping would mediate (augment) the effects of perceived stress on depression.

\section{Method}

\section{Participants}

There were 510 participants with complete data, 343 boys and 167 girls. Participants were between the ages of 14 and 18 $(M=15.50, S D=.89)$. Participants were from rural $(n=123$, schools outside large cities in New South Wales, Australia) and urban ( $n=387$, schools in Sydney, NSW, Australia) areas. All were private schools but with diverse student populations in terms of family socioeconomic background given the schools' online profile, location, and religious denomination. The schools were all non-government and included three independent and three low-fee paying Catholic schools.

Of 697 questionnaires 187 were excluded as they were empty or with very limited information. Thus there was a participation rate of $73 \%$. No comparison of excluded versus included participants was possible due to the extent of missing data in the excluded group.

According to the norms of the depression scale, about $14 \%$ of the sample had "extremely severe" depression, 7\% "severe", $15 \%$ "moderate", $10 \%$ "mild", and 53\% had "normal" levels.

\section{Measures}

Depression was measured by the depression subscale on the Depression, Anxiety, and Stress Scales (DASS-21; Lovibond \& Lovibond, 1995). The DASS-21 has good internal consistency with alphas ranging from .87 to .94 for each of its 7 -item sub-scales, and adequate validity in a variety of populations (Antony, Bieling, Cox, Enns, \& Swinson, 1998). The scale is a 4 point Likert scale ranging from 0 (Did not apply to me) to 3 (Applied to me very much, or most of the time) to answer questions such as "I felt that life was meaningless". In the present study, the internal reliability for the depression sub-scale was .90. Total scores were averaged rather than summed across items to keep the link between the total score and the anchors on the 4-point scale.

Perceived stress was measured using the Perceived Stress Scale (PSS; Cohen, Kamarck, \& Mermelstein, 1983). This is a 10 -item measure of how often respondents have viewed their life situations as stressful over the past month (Cohen et al., 1983), such as "In the last month how often have you felt that you were unable to control the important things in your life". The scale is a 5-point Likert scale, ranging from 0 (Never) to 4 (Very often). Items $4,5,7$, and 8 are reverse-scored. The PSS is the most widely used psychological instrument for measuring the perception of stress (Cohen, 1988), and is correlated with a variety of health symptoms and help-seeking behaviors (Cohen et al., 1983). In the present study, internal reliability for the PSS was .85 .

The Measure of Adolescent Coping Strategies (MACS; Sveinbjornsdottir, 2005; Sveinbjornsdottir \& Thorsteinsson, 2012) is a 34-item scale, including five primary factors: (a) distraction/stoicism, (b) acting out, (c) rumination, (d) seeking social support, and (e) self-care. These five factors comprise two dimensions, one adaptive (a, d, and e) and the other maladaptive (b and $\mathrm{c}$ ). It has cross-cultural validation and good test-retest reliability and adequate internal reliability compared with other adolescent coping scales (for a review of other measures see Sveinbjornsdottir \& Thorsteinsson, 2008). The MACS was standardized through exploratory factor analysis and the participation of 3034 Australian adolescents and 6908 Icelandic adolescents. The factor structure has been tested using confirmatory factor analysis and found to be good, $C F I=.94$, $T L I=.92, G F I=.95$, RMSEA $=.054$ [90\% CI .045, .064], and $S R M R=.063$ (Sveinbjornsdottir \& Thorsteinsson, 2012). Participants were asked to think of a stressful situation they had experienced during the recent past (i.e., something that happened at school, in their family, relations with other people, or their health). They were then asked to circle a number for each item on a 4-point Likert scale ranging from 0 (I did not use) to 3 (I used almost all the time). In the present study, the MACS had an adequate internal reliability for distraction/stoicism 
of .72 , acting out .77 , rumination .73 , seeking social support .70 , and self-care 71 .

Social support was measured using the Social Support Questionnaire Short Form (SSQ6; Sarason, Sarason, Shearin, \& Pierce, 1987), a psychometrically sound and conveniently administered instrument. It has good internal reliability and correlates highly with the full-scale SSQ (Sarason et al., 1987). The items have two parts. The first part of each item assesses the number of available others (SSQN) the participant has who he/she can rely on in times of need. An example of the type of question is "Who do you know whom you can trust with information that could get you into trouble". In the second part of the item, the participant is asked to indicate on a 6-point Likert scale how satisfied (SSQS) he/she is with the overall support from the number of people indicated in the first part ranging from 1 (Very dissatisfied) to 6 (Very satisfied). In the present study, internal reliability for the SSQS was .86 and for the SSQN .93.

\section{Procedure}

Ethics approval was granted by the university's human ethics committee and participating schools. Participants were recruited from schools in urban areas (Sydney, NSW, Australia) and in rural areas of NSW (i.e., schools outside large cities). Teachers approached students in their classes about participating in the study and consent forms were sent home to the parents or guardians of the students. A day was organized for the participating school to complete the questionnaires.

One participant had missing values for social support satisfaction and number. These values were estimated using the expectation-maximization (EM) algorithm within SPSS missing values analysis. The following variables were used to predict the missing values: age, sex, social support satisfaction and number, DASS21 (depression, anxiety, and stress), MACS (distraction/stoicism, acting out, rumination, seeking social support, and self-care), and perceived stress.

SPSS (version 20) was used for routine statistical analyses in raw and processed data with statistical significance set at .05 and expected mean differences to be above 0.30 standard deviation units $(d)$. AMOS (version 20) was used for structural equation modeling (SEM): modeling mediators of the perceived stress-depression relationship. Recommendations by Kline (2005) were used to select fit indices. The Comparative Fit Index $(C F I)$ ranges from 0 to 1 , with those above .90 suggesting good fit, for the Root Mean Square Error of Approximation (RMSEA) and Squared Root Mean Residual (SRMR) a value of 0 represents perfect fit. RMSEA values below .08 and SRMR values. 10 are generally interpreted as favorable. All parameters for the model were estimated using AMOS' maximum likelihood algorithm.

Further testing of potential mediators was conducted using the bootstrap method by Preacher and Hayes (2004) replacing the Sobel test. This method compares coefficients for the total effect, path c (effects of independent variable on the dependent variable without any mediators) with the coefficient for the direct effect c' (effects of independent variable on the dependent variable with any mediators included). There is significant mediation if the c-c' difference is larger than zero based on a $95 \%$ bootstrap generated confidence interval. Unstandardized $b$ coefficient with $95 \%$ confidence interval is reported, in square brackets, to show if the proposed mediator mediates the pro- posed relationship or not.

\section{Results}

There was no statistically significant difference between urban and rural populations for perceived stress or depression all effect sizes being small (see Table 1), thus the samples were analyzed as one. Social support satisfaction and number were both significantly associated with depression (see Table 2). High maladaptive coping, acting out and rumination were associated with high depression. High acting out was associated with low social support while high rumination was associated with low support satisfaction but not low support number (see Table 2). Examination of the mediation effects of social support and coping found that adaptive coping including distraction/stoicism $b=.01[-.01, .04]$, seeking social support $b=.00$ $[-.01, .01]$, and self-care $b=.00[-.01, .01]$ did not mediate the effects of perceived stress on depression. Acting out, $b=.09$ $[.05, .13]$, and rumination, $b=.09[.04, .14]$ were partial mediators of the relationship between perceived stress and depression. Social support satisfaction, $b=.04[.01, .07]$ and number, $b=.04[.02, .06]$ were partial mediators of the effects of perceived stress on depression.

SEM was used to model these mediation effects showing that perceived stress, maladaptive coping, and social support explained about $66 \%$ of the variance in depression (see Figure 1).

\section{Discussion}

The first hypothesis was not supported with little difference in perceived stress and depression levels between rural and urban adolescents contradicting suggestions by Day et al. (2000), Crowell et al. (1986), and Quine et al. (2010). The second hypothesis was supported with high depression and low social support (satisfaction and number of supporters) levels being associated, thus supporting previous research and theory (Burke \& Weir, 1978; Cohen \& Wills, 1985; Dumont \& Provost, 1999; Levitt et al., 1993). High maladaptive coping was associated with high depression and low social support thus supporting the third hypothesis. The fourth hypothesis was supported with social support mediating the effects of perceived stress on depression expanding on the findings by Day et al. (2000) and Weber et al. (2010). The fifth hypothesis was not supported in that adaptive coping did not attenuate the effects of perceived stress on depression. The final hypothesis was supported, finding that maladaptive coping augmented the effects of perceived stress on depression.

The resulting model, as shown in Figure 1, supported the hypotheses further showing that it is important to target both maladaptive coping and social support to reduce the impact of perceived stress on depression. The results showed that high rumination (e.g., hoping that the problem will disappear or

Table 1.

Perceived stress and depression means (SD) for all, urban, and rural participants with a comparison of urban and rural participants.

\begin{tabular}{lcccc}
\hline Measure & $\begin{array}{c}\text { All } \\
(\mathrm{N}=510)\end{array}$ & $\begin{array}{c}\text { Urban } \\
(\mathrm{n}=387)\end{array}$ & $\begin{array}{c}\text { Rural } \\
(\mathrm{n}=123)\end{array}$ & $\mathrm{d}(\mathrm{CI} 95 \%)$ \\
\hline $\begin{array}{l}\text { Perceived } \\
\text { Stress }\end{array}$ & $1.79(.75)$ & $1.78(.74)$ & $1.85(.76)$ & $.09[-.11, .30]$ \\
Depression & $.84(.81)$ & $.83(.80)$ & $.88(.84)$ & $.06[-.14, .26]$ \\
\hline
\end{tabular}


Table 2.

Correlation matrix for key variables $(\mathrm{N}=510)$.

\begin{tabular}{|c|c|c|c|c|c|c|c|c|}
\hline Variable & 1 & 2 & 3 & 4 & 5 & 6 & 7 & 8 \\
\hline 1. Perceived stress & - & & & & & & & \\
\hline 2. Support satisfaction & $-.28^{* *}$ & - & & & & & & \\
\hline 3. Support number & $-.19^{* *}$ & $.47^{* *}$ & - & & & & & \\
\hline 4. Distraction/stoicism & $-.25^{* *}$ & $.18^{* *}$ & $.28^{* *}$ & - & & & & \\
\hline 5. Acting out & $.37^{* *}$ & $-.22^{* *}$ & $-.19^{* *}$ & $-.12^{* *}$ & - & & & \\
\hline 6. Rumination & $.51^{* *}$ & $-.11^{*}$ & -.02 & -.03 & $.40^{* *}$ & - & & \\
\hline 7. Seeking support & -.04 & $.23^{* *}$ & $.33^{* *}$ & $.43^{* *}$ & .01 & $.20^{* *}$ & - & \\
\hline 8. Self-care & $-.11^{*}$ & $.18^{* *}$ & $.26^{* *}$ & $.47^{* *}$ & .03 & .08 & $.50^{* *}$ & - \\
\hline 9. Depression & $.66^{* *}$ & $-.30^{* *}$ & $-.30^{* *}$ & $-.22^{* *}$ & $.47^{* *}$ & $.51^{* *}$ & $-.11^{*}$ & $-.12^{* *}$ \\
\hline
\end{tabular}

" $\mathrm{p}<.05$ (two-tailed), ${ }^{* *} \mathrm{p}<.01$ (two-tailed).

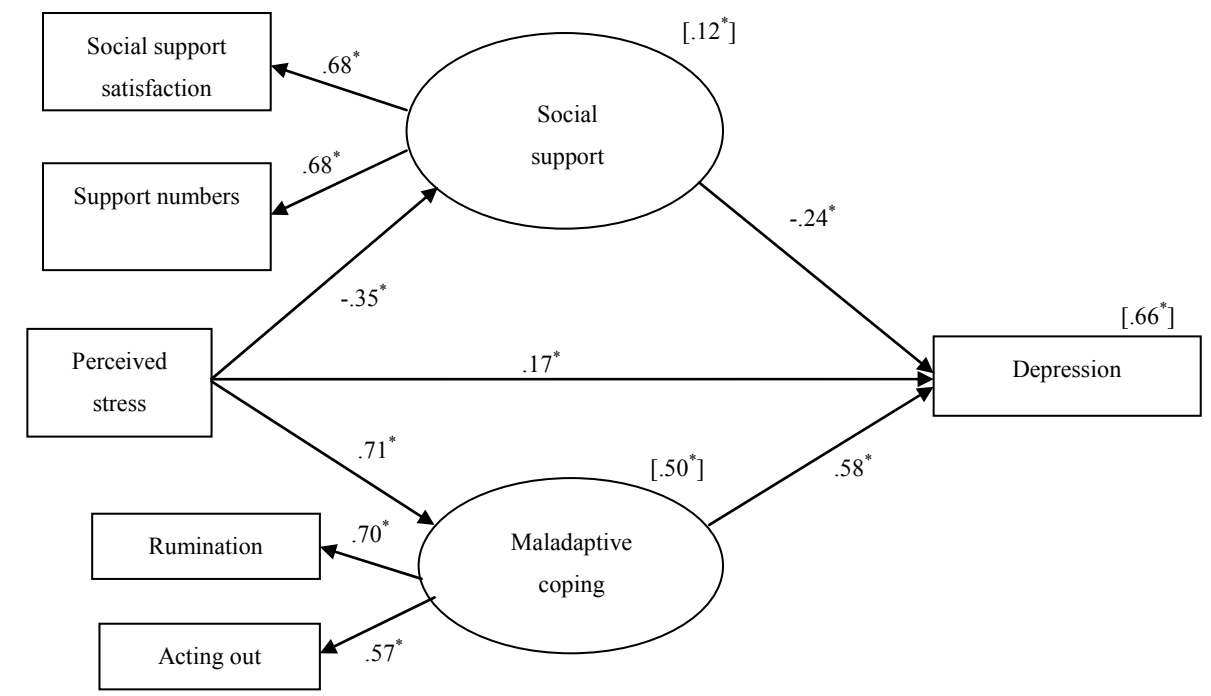

Figure 1.

The mediation of acting out and rumination of the perceived stress-depression relationship. Percentage of variance explained given in square brackets. $\chi^{2}(18)=68.29, p<.001, C F I=.970$, TLI $=.926$, RMSEA $=.052(.040, .066)$, SRMR $=.044 .{ }^{*} p<.05$ (one-tailed).

hoping for a miracle) and high acting out (e.g., aggressive behavior) were important predictors of high depression levels along with low social support (satisfaction and number). The model in Figure 1 thus supports and expands on previous findings presenting a testable model. The model supports previous findings suggesting that engaging in maladaptive coping strategies has negative repercussions for the adolescent (DeLongis \& Holtzman, 2005) and that social support attenuates the impact of stress (e.g., Burke \& Weir, 1978; Cohen \& Wills, 1985; Day et al., 2000; Dumont \& Provost, 1999; Levitt et al., 1993).

Although the correlation between adaptive coping and depression was in the expected direction, adaptive coping was not a significant mediator of the perceived stress to depression relationship. According to Delongis and Holtzman (2005), the inconsistent findings in relation to adaptive coping may be due to the nature of the situation evoking perceived stress levels, the social context in which the coping occurs, and the personality of the individual. The present findings might be interpreted to mean that adaptive coping is 'overshadowed' by social support, a construct related to seeking social support (Sveinbjornsdottir \& Thorsteinsson, 2012).

The small differences between the urban and rural adolescent samples may have been due to a lack of any real differences between these populations. However, there may be differences in the type of stressful situations experienced by these groups and not in the level of perceived stress, at least for adolescents. Findings from social geography research (Boyd \& Parr, 2008) have not really been integrated into a mental health model capturing the differences between urban and rural adolescents, thus future studies might operationalise urban and rural based on social geography research to help clarify any potential differences between urban and rural adolescents.

Cross-sectional studies do not address causal directions. Therefore, more work is required to model the effects of coping and social support on the stress to depression relationship. Longitudinal and experimental studies are needed to try and address causal pathways. Despite a good participation rate, larger samples are needed to examine sex and location differences. The 


\section{E. B. THORSTEINSSON ET AL.}

social support pathway may be more "important" for rural adolescents than urban adolescents (Baume \& Clinton, 1997) suggesting that remote rural areas may be more at risk than rural towns that are not so remote; in the present study remote rural towns were not significantly represented.

\section{Conclusion}

These findings suggest that improving social support satisfaction and networks may benefit adolescents through reduced impact of perceived stress on depression levels. Similarly, reducing maladaptive coping behavior may also lessen the impact of perceived stress on depression. Consequently, in order to replace maladaptive coping with adaptive coping and to improve social networks, adolescents need to become aware of and understand the impact their ways of coping and social networks may have on their well-being. For that purpose, education in general and cognitive behavior therapy in clinical cases might prove useful.

\section{REFERENCES}

Aisbett, D. L., Boyd, C. P., Francis, K. J., Newnham, K., \& Newnham, K. (2007). Understanding barriers to mental health service utilization for adolescents in rural Australia. Rural and Remote Health, 7, 1-10.

Andersen, S. L., \& Teicher, M. H. (2008). Stress, sensitive periods and maturational events in adolescent depression. Trends in Neurosciences, 31, 183-191. doi:10.1016/j.tins.2008.01.004

Antony, M. M., Bieling, P. J., Cox, B. J., Enns, M. W., \& Swinson, R. P. (1998). Psychometric properties of the 42-item and 21-item versions of the Depression Anxiety Stress Scales in clinical groups and a community sample. Psychological Assessment, 10, 176-181. doi:10.1037/1040-3590.10.2.176

Baume, P. J. M., \& Clinton, M. E. (1997). Social and cultural patterns of suicide in young people in rural Australia. Australian Journal of Rural Health, 5, 115-120 doi:10.1111/j.1440-1584.1997.tb00251.x

Boyd, C. P., \& Parr, H. (2008). Social geography and rural mental health research. Rural and Remote Health, 8, 1-5.

Burke, R. J., \& Weir, T. (1978). Benefits to adolescents of informal helping relationships with their parents and peers. Psychological Reports, 42, 1175-1184. doi:10.2466/pr0.1978.42.3c.1175

Byrne, D. G., Davenport, S. C., \& Mazanov, J. (2007). Profiles of adolescent stress: The development of the Adolescent Stress Questionnaire (ASQ). Journal of Adolescence, 30, 393-416. doi:10.1016/j.adolescence.2006.04.004

Cohen, S., Kamarck, T., \& Mermelstein, R. (1983). A global measure of perceived stress. Journal of Health and Social Behavior, 24, 385396. doi: $10.2307 / 2136404$

Cohen, S. (1988). Perceived stress in a probability sample of the United States. In S. Spacapan, \& S. Oskamp (Eds.), The social psychology of health. The Claremont Symposium on applied social psychology (pp. 31-67). Thousand Oaks, CA: Sage.

Cohen, S., \& Wills, T. A. (1985). Stress, social support, and the buffering hypothesis. Psychological Bulletin, 98, 310-357. doi: $10.1037 / 0033-2909.98 .2 .310$

Copeland, W. E., Shanahan, L., Costello, E. J., \& Angold, A. (2009). Childhood and adolescent psychiatric disorders as predictors of young adult disorders. Archives of General Psychiatry, 66, 764-772. doi:10.1001/archgenpsychiatry.2009.85

Crowell, B. A. J., George, L. K., Blazer, D., \& Landerman, R. (1986). Psychosocial risk factors and urban/rural differences in the prevalence of major depression. The British Journal of Psychiatry, 149, 307-314. doi:10.1192/bjp.149.3.307

Day, C., Kane, R. T., \& Roberts, C. (2000). Depressive symptomatology in rural Western Australia: Prevalence, severity and risk and protective factors. Australian Journal of Psychology, 52, 51-58. doi: $10.1080 / 00049530008255367$

DeLongis, A., \& Holtzman, S. (2005). Coping in context: The role of stress, social support, and personality in coping. Journal of Personality, Special Issue: Advances in Personality and Daily Experience, 73, 1633-1656. doi:10.1111/j.1467-6494.2005.00361.x

Dumont, M., \& Provost, M. A. (1999). Resilience in adolescents: Protective role of social support, coping strategies, self-esteem, and social activities on experience of stress and depression. Journal of Youth and Adolescence, 28, 343-363. doi:10.1023/A:1021637011732

Ebata, A. T., \& Moos, R. H. (1991). Coping and adjustment in distressed and healthy adolescents. Journal of Applied Developmental Psychology, 12, 33-54. doi:10.1016/0193-3973(91)90029-4

Galaif, E. R., Sussman, S., Chou, C. P., \& Wills, T. A. (2003). Longitudinal relations among depression, stress, and coping in high risk youth. Journal of Youth and Adolescence, 32, 243-258. doi:10.1023/A:1023028809718

Jorgensen, S. R., \& Dusek, J. B. (1990). Adolescent adjustment and coping strategies. Journal of Personality, 58, 503-513. doi:10.1111/j.1467-6494.1990.tb00240.x

Jose, P. E., D’Anna, C. A., Cafasso, L. L., Bryant, F. B., Chiker, V., Gein, N., \& Zhezmer, N. (1998). Stress and coping among Russian and American early adolescents. Developmental Psychology, 34, 757-769. doi:10.1037/0012-1649.34.4.757

Kline, R. B. (2005). Principles and practice of structural equation modeling (2nd ed.). New York: Guilford Press.

Kosterman, R., Hawkins, J. D., Mason, W. A., Herrenkohl, T. I., Lengua, L. J., \& McCauley, E. (2010). Assessment of behavior problems in childhood and adolescence as predictors of early adult depression. Journal of Psychopathology and Behavioral Assessment, 32, 118-127. doi:10.1007/s10862-009-9138-0

Levitt, M. J., Guacci Franco, N., \& Levitt, J. L. (1993). Convoys of social support in childhood and early adolescence: Structure and function. Developmental Psychology, 29, 811-818. doi:10.1037/0012-1649.29.5.811

Lovibond, P. F., \& Lovibond, S. H. (1995). The structure of negative emotional states: Comparison of the Depression Anxiety Stress Scales (DASS) with the Beck Depression and Anxiety Inventories. Behaviour Research and Therapy, 33, 335-343. doi:10.1016/0005-7967(94)00075-U

Moksnes, U. K., Byrne, D. G., Mazanov, J., \& Espnes, G. A. (2010). Adolescent stress: Evaluation of the factor structure of the Adolescent Stress Questionnaire (ASQ-N). Scandinavian Journal of Psychology, 51, 203-209. doi:10.1111/j.1467-9450.2009.00803.x

Murberg, T. A., \& Bru, E. (2005). The role of coping styles as predicttors of depressive symptoms among adolescents: A prospective study. Scandinavian Journal of Psychology, 46, 385-393. doi:10.1111/j.1467-9450.2005.00469.x

Ozbay, F., Fitterling, H., Charney, D., \& Southwick, S. (2008). Social support and resilience to stress across the life span: A neurobiologic framework. Current Psychiatry Reports, 10, 304-310. doi:10.1007/s11920-008-0049-7

Preacher, K. J., \& Hayes, A. F. (2004). SPSS and SAS procedures for estimating indirect effects in simple mediation models. Behavior Research Methods, Instruments, \& Computers, 36, 717-731. doi:10.3758/BF03206553

Quine, S., Bernard, D., Booth, M., Kang, M., Usherwood, T., Alperstein, G. et al. (2003). Health and access issues among Australian adolescents: A rural-urban comparison [Electronic Version]. Rural and Remote Health, 3, 1-11.

Recklitis, J., \& Noam, G. (1999). Clinical and developmental perspectives on adolescent coping. Child Psychiatry and Human Development, 30, 87-101. doi:10.1023/A:1021998217862

Reinherz, H. Z., Stewart Berghauer, G., Pakiz, B., Frost, A. K., Moeykens, B. A., \& Holmes, W. M. (1989). The relationship of early risk and current mediators to depressive symptomatology in adolescence. Journal of the American Academy of Child \& Adolescent Psychiatry, 28, 942-947. doi:10.1097/00004583-198911000-00021

Romeo, R. D. (2010). Adolescence: A central event in shaping stress reactivity. Developmental Psychobiology, 52, 244-253.

doi:10.1002/dev.20437 


\section{E. B. THORSTEINSSON ET AL.}

Sarason, I. G., Sarason, B. R., Shearin, E. N., \& Pierce, G. R. (1987). A brief measure of social support: Practical and theoretical implications. Journal of Social and Personal Relationships, 4, 497-510. doi:10.1177/0265407587044007

Schmeelk-Cone, K. H., \& Zimmerman, M. A. (2003). A longitudinal analysis of stress in African American youth: Predictors and outcomes of stress trajectories. Journal of Youth and Adolescence, 32, 419-430. doi:10.1023/A:1025934301468

Seiffge-Krenke, I., Aunola, K., \& Nurmi, J.-E. (2009). Changes in stress perception and coping during adolescence: The role of situational and personal factors. Child Development, 80, 259-279. doi:10.1111/j.1467-8624.2008.01258.x

Seiffge-Krenke, I., \& Klessinger, N. (2000). Long-term effects of avoidant coping on adolescents' depressive symptoms. Journal of Youth and Adolescence, 29, 617-630. doi:10.1023/A:1026440304695

Seiffge-Krenke, I., Weidemann, S., Fentner, S., Aegenheister, N., \& Poeblau, M. (2001). Coping with school-related stress and family stress in healthy and clinically referred adolescents. European Psychologist, 6, 123-132. doi:10.1027//1016-9040.6.2.123

Skitch, S. A., \& Abela, J. R. Z. (2008). Rumination in response to stress as a common vulnerability factor to depression and substance misuse in adolescence. Journal of Abnormal Child Psychology, 36, 10291045. doi:10.1007/s10802-008-9233-9

Sorenson, S. B., Rutter, C. M., \& Aneshensel, C. S. (1991). Depression in the community: An investigation into age of onset. Journal of Consulting and Clinical Psychology, 59, 541-546. doi:10.1037/0022-006X.59.4.541
Sveinbjornsdottir, S. (2005). Bjargráð unglinga og mæling peirra: Bjargráðakvarðinn MACS (Measure of Adolescent Coping Strategies). In Ú. Hauksson (Ed.), Rannsóknir i félagsvísindum VI (pp. 487-500). Reykjavík: Félagsvísindastofnun Háskóla Î́slands.

Sveinbjornsdottir, S., \& Thorsteinsson, E. B. (2008). Adolescent coping scales: A critical psychometric review. Scandinavian Journal of Psychology, 49, 533-548. doi:10.1111/j.1467-9450.2008.00669.x

Sveinbjornsdottir, S., \& Thorsteinsson, E. B. (2012). A psychometriccally derived theory on adolescent coping: Development of the Measure of Adolescent Coping Strategies (MACS). Unpublished raw data.

Thorsteinsson, E. B., \& James, J. E. (1999). A meta-analysis of the effects of experimental manipulations of social support during laboratory stress. Psychology \& Health, 14, 869-886. doi:10.1080/08870449908407353

Thorsteinsson, E. B., James, J. E., Douglas, M. E., \& Omodei, M. M. (2011). Effects of social support on cardiovascular and cortisol reactivity during passive and active behavioural challenge. Journal of Psychiatry, Psychology and Mental Health, 3, 1-12.

Tolor, A., \& Fehon, D. (1987). Coping with stress: A study of male adolescents' coping strategies as related to adjustment. Journal of Adolescent Research, 2, 33-42. doi:10.1177/074355488721003

Weber, S., Puskar, K. R., \& Ren, D. (2010). Relationships between depressive symptoms and perceived social support, self-esteem, \& optimism in a sample of rural adolescents. Issues in Mental Health Nursing, 31, 584-588. doi:10.3109/01612841003775061 